Gut, 1977, 18, 919-920

\title{
Technique
}

\section{Device for obtaining multiple simultaneous samples of intestinal contents during perfusion studies in man}

\author{
J. W. MAtSeShe, J.-R. MALAgeladA, AND S. F. PHILlipS \\ From the Gastroenterology Unit, Mayo Clinic and Mayo Medical School, Rochester, Minnesota 55901, USA
}

SUMMARY A system is described for obtaining frequent simultaneous samples from three jejunal sites. It can be easily made from materials ordinarily available in any laboratory.

Multiple, and often, simultaneous samples of intestinal contents are required when transit times and absorption rates of test meals or perfusion solutions along the gastrointestinal tract are to be determined (Dillard et al., 1965; Barreiro et al., 1968; Whalen et al., 1966; Johansson, 1974). When high flow rates are employed, as during certain perfusion studies, luminal contents are sampled rather easily by siphonage. However, sampling may be erratic when attempts are made to recover lesser flows of

Received for publication 29 April 1977 intestinal contents or when studies are performed after test meals. We describe here a system which we found very helpful for obtaining frequent simultaneous samples from three jejunal loci. Predetermined amounts of postprandial intestinal contents were recoverable at specified sites and at regular intervals.

We constructed the device from material ordinarily found in most hospitals and laboratories. We used the following components: an intermittent suction pump (Ohio Medical Products, Madison, WI); branching tubes (Pharmaseal Laboratories,

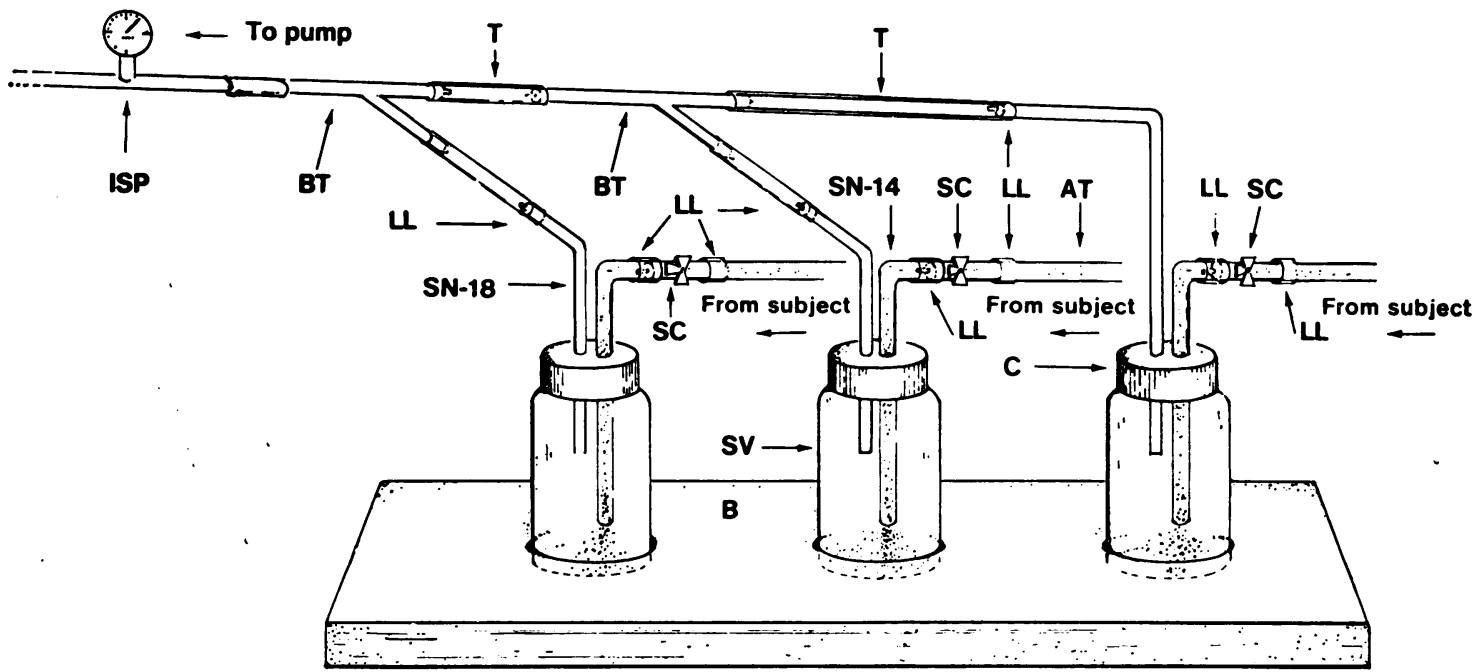

Figure Sampling device for use in intestinal perfusion studies. AT: aspiration tubing. LL: Luer lock connection. SC: three way stopcock. SN-14: blunt 14-gauge stainless steel needle. C: screw cap. SV: st trage vial. SN-18: blunt 18-gauge stainless steel needle. T: silastic tubing. BT: branching tube. ISP: intermittent suction pump. B: board for holding vials. 
Glendale, CA); silastic tubing (0.125 in. I.D., Dow Corning Corporation, MI); a blunt stainless steel needle, 14-gauge, $5.4 \mathrm{~cm}$, with one end soldered onto a Luer-lock connexion; another blunt stainless steel needle, 18-gauge, $2.2 \mathrm{~cm}$, also soldered onto a Luer-lock connexion; $8 \mathrm{ml}$ and $\mathrm{ml} 6$ capacity glass storage vials (Wheaton Scientific, Melville, NJ); a three-way stopcock (K-75, Pharmaseal Laboratories, Glendale, CA); and a piece of board, $24 \mathrm{~cm} \times$ $12 \mathrm{~cm} \times 2 \mathrm{~cm}$ with a series of circular holes, $0.5 \mathrm{~cm}$ deep, to hold the storage vials.

The Figure illustrates the major components. Each aspiration tube (AT) was connected to a 14-gauge blunt stainless steel needle ( $\mathrm{SN}-14)$ with a three way stopcock (SC) and a Luer-lock connection (LL). The stopcock provided easy access to the system for removing intermittent blockages. The needle was bent so that its shaft passed through the screw cap (C) of a storage vial (SV). The point at which the needle entered the cap was sealed with quick-stick epoxy. A smaller needle (SN-18) passed through a second hole in the screw-cap. This needle was also bent so that its base had a Luer- lock connexion attached to silastic tubing $(T)$; this in turn was connected to an intermittent suction pump (ISP) via branching tubes (BT). Equal suction was thus distributed to all aspiration sites.

At the start of perfusion, the storage vials were screwed tightly to their caps and intermittent suction was adjusted to 60 to $80 \mathrm{~mm} \mathrm{Hg}$ pressure. The flow of intestinal samples was easily regulated, and desired amounts obtained, by adjusting the three way stopcock. We used this device to obtain samples of $3 \mathrm{ml}$ every five minutes from three aspiration sites $(30 \mathrm{~cm}$ apart) in the proximal jejunum after an 'ordinary' mixed solid-liquid test meal had been ingested by five healthy volunteers, as described by Malagelada et al. (1976). During a five hour postprandial period, samples were obtained during more than $80 \%$ of the periods at each site. Pump pressures below $60 \mathrm{~mm} \mathrm{Hg}$ did not sustain a smooth regular flow of intestinal contents and pressures above $80 \mathrm{~mm} \mathrm{Hg}$ appeared unnecessary.

We found the method efficient and economical. The apparatus can be made easily by any laboratory and the materials are readily available.

This work was supported in part by funds from Kellogg's Company, Battle Creek, Michigan.

\section{References}

Dillard, R. L., Eastman, H., and Fordtran, J. S. (1965). Volume-flow relationship during the transport of fluid through the human small intestine. Gastroenterology, 49, 58-66.

Barreiro, M. A., McKenna, R. D., and Beck, I. T. (1968). Determination of transit time in the human jejunum by the single-injection indicator-dilution technic. American Journal of Digestive Diseases 13, 222-233.

Whalen, G. E., Harris, J. S., Geenen. J. E., and Soergel, K. H. (1966). Sodium and water absorption from the human small intestine. Gastroenterology, 51, 975-984.

Johansson, C. (1974). Studies of gastrointestinal interactions. Scandinavian Journal of Gastroenterology, suppl. 28, 9.

Malagelada, J. R., Longstreth, G. F., Summerskill, W. H. J., and Go, V. L. W. (1976). Measurements of gastric functions during digestion of ordinary solid meals in man. Gastroenterology, 70, 203-210. 